\title{
Magnitude and associated factors of unmet need of modern family planning among reproductive age women in south Gondar zone, North West Ethiopia, 2017
}

Muluken Genetu Chanie ( $\square$ kinfemich21@yahoo.com )

Wollo University https://orcid.org/0000-0001-7059-1449

Gojjam Eshetie Ewuneite

Denbya primary hospital

Mamo Dereje

FMoH of Ethiopia

\section{Research}

Keywords: unmet need, family planning, women, Ethiopia

Posted Date: May 14th, 2020

DOI: https://doi.org/10.21203/rs.3.rs-27435/v1

License: (c) (i) This work is licensed under a Creative Commons Attribution 4.0 International License.

Read Full License 


\section{Abstract}

Background: The aim of this study was to identify the prevalence and associated factors of unmet need of modern family planning among reproductive age women in south Gondar zone.

Methods: A community based cross-sectional study design was conducted in south Gondar zone among 528 reproductive age women. Data were collected with pre-tested, structured, interviewer administered questionnaires. Data were coded and entered into Epi info version 7 and exported to SPSS version 20. Bivariable and multivariable logistic regression models were applied. A P-value 0.05 was considered to declare a result as significant at $95 \% \mathrm{Cl}$.

Result: -The overall unmet need in this study area was $22.6 \%$, from whom $15.1 \%$ respondents were wanted children later and $7.5 \%$ were wanted no more children. Women who had been visited by health care providers within 12 months prior to the study, current menstrual status of women, desired number of children and induced abortion were found to be the main factors. Conclusion: -Unmet need for family planning was found to be high in the study area as compared to national and regional prevalence. Women who had been visited by health care providers, Current menstruation status, desired number of children and induced abortion were significantly associated with unmet need of modern family planning. Healthcare providers recurrent visit need to be performed by family planning providers and women empowerment to decide numbers of children are very important areas to decrease unmet need of modern FP.

\section{Plain English Summary}

Women who are sexually active and want to avoid becoming pregnant but are not using contraception are termed have unmet need for family planning. Reducing unmet need of modern family planning can prevent around $30 \%$ of maternal death, reduce maternal mortality by $20 \%$, and avert 36 million women of healthy life lost each year. Helping women and couples plan their family size and increase access to contraceptive service help to reduce unmet need of family planning which improves maternal health and promoting women empowerment.

Five hundred twenty eight reproductive age women were participated in this study. Pre-tested, structured, interviewer administered questionnaires were used for data collection. Data were checked for completeness, cleaned, coded and entered into Epi-info v.7 and transferred to SPSS V. 20 for analysis. At multivariable logistic regression analysis significant variables were identified for intervention at P-value 0.05 with $95 \% \mathrm{Cl}$.

The overall unmet need of modern family planning was found $22.6 \%$, from whom $15.1 \%$ of respondents were wanted children later and $7.5 \%$ were wanted no more children in life. Women who had been visited at home healthworker within 12 months prior to the study, current menstruation of women, desired number of children and history of induced abortion were found significant for unmet need of family 
In conclusion, Unmet need for family planning was high in this study as compared to national figures. The above listed significant factors were very informative for planners and decision makers to act on behalf of women for satisfying their family planning need.

\section{Background}

Women who are sexually active and want to avoid becoming pregnant but are not using contraception are called unmet need for family planning. Unmet need of family planning has two divisions. These are unmet need for spacing or want later and unmet need for limiting (1).

About 74 million unintended pregnancies are reported each year in developing countries. Most of them are women using no contraception or using traditional methods. There would be a chance to avoid 52 million unmet needs and 70,000 women from pregnancy related deaths if all unmet needs were met (1). Currently, in the world unmet need of modern family planning is still not low especially in developing countries there is greater prevalence of unmet need of family planning. In 2014 USAID report unmet need of modern family planning among young women is different in different region of the world. West and central Africa which is $29.3 \%$ in young married women and $25.9 \%$ in older married women, East and South Africa $25.5 \%$ in younger married women and $25 \%$ in older married women, Latin America and Caribbean 24.5 in younger married women and. $15.6 \%$ in older married women and Middle East and North Africa $10.8 \%$ in younger married women and $12.6 \%$ in older women (5).

Ethiopia has high density population and also the population is increasing rapidly. The use of modern family planning especially long term FP is still low. Consequently, unmet need of FP is still not reduced as needed (7). In Ethiopian Demographic and Health Survey 2016, prevalence of unmet need of family planning is $22 \%(3)$.

Unmet need of family planning become one of the reasons for unwanted pregnancy, especially in developing countries like Ethiopia $(8,9)$. If unmet need become decreased, Contraceptive prevalence rate will increase from $36-55 \%$ among married women of the country (3).

In the context of Ethiopian situation, even though there are studies on prevalence and factors of modern family planning among married women, still there is higher magnitude of unmet need of family planning even under the influence of under reporting, when it is seen according to Ethiopian 2020 family planning plan which is $10 \%$ (2). Currently, there are some important reasons for unmet need of modern family planning such as low performance of health staffs on family planning services especially on counseling about importance of modern methods compared to traditional methods, tell about side effects clearly and effectively, address client questions, manage side effects and complications effectively, allow free choice of family planning methods and detail discussion on misconceptions raised in the community.

So, this study were relevant to look into the problem and gives more information about prevalence and associated factors of unmet need of modern family planning among married women in North Gondar 


\section{Methods}

\subsection{Study design and setting}

A Community based cross sectional study design was conducted in south Gondar zone from 0923/01/2017. South Gondar is one of the 11 zonal administration in Amhara regional state, Ethiopia. It has 13 woredas, 32 urban and 138 rural kebeles. There are 12 primary hospitals, 73 health centers, and 145 health posts. All health facilities provide family planning services. It has $2,039,077$ total populations (Health department's report of 2016).

\subsection{Population}

All reproductive age women found in south Gondar zone were used as source population of the study. Reproductive age women live in selected kebeles during the data collection period were the study population of this study.

\subsection{Inclusion and exclusion criteria}

All reproductive age group women were included in the study. But reproductive age women who were severely ill and who lived less than 6 months in the selected kebeles were excluded.

\subsection{Sample size determination and sampling procedure}

Sample size was determined using a single population proportion formula based on the following assumptions: prevalence of unmet need of modern family planning $22 \%$ (3); degree of margin $5 \% ; 1.5$ design effect and $10 \%$ non-response rate at $5 \%$ level of significance:

$\mathrm{n}=(\mathrm{Za} / 2)^{2} \mathrm{p}(1-\mathrm{p}) / \mathrm{d}^{2}$

$=(1.96)^{2} \times(0.22) \times(0.78) /(0.05) 2=263$

$=263 \times 1.5($ design effect $)=396$ by adding $10 \%$ non-response rate $=396+40=436$

Sample size using double population proportion was determined for three variable from previous studies and the final results were found higher than the sample size calculated above using single population proportion and the highest among all the samples was used. (Table 1). Therefore, the final sample size used was 528 reproductive age women. 
Table 1

Sample size calculation with double population proportion formula using Epi-info version 7 for unmet need of modern FP in South Gondar, Ethiopia, $2017(7,9,15)$.

\begin{tabular}{|c|c|c|c|c|c|c|c|}
\hline Factors & $\begin{array}{l}\text { \%outcome } \\
\text { exposed }\end{array}$ & Power & $\begin{array}{l}\text { \% outcome } \\
\text { unexposed }\end{array}$ & OR & $10 \%$ & $\begin{array}{l}\text { Design } \\
\text { effect }\end{array}$ & $\begin{array}{l}\text { Sample } \\
\text { size }\end{array}$ \\
\hline Partner disapproval & 11 & \multirow[t]{3}{*}{$80 \%$} & 41 & 2.63 & 32 & \multirow[t]{3}{*}{1.5} & 528 \\
\hline $\begin{array}{l}\text { Have you ever used } \\
\text { FP? No }\end{array}$ & 43.7 & & 56.3 & 2.29 & 23 & & 379 \\
\hline $\begin{array}{l}\text { Number of living } \\
\text { children(3/4) }\end{array}$ & 32.2 & & 67.8 & 2.84 & 20 & & 324 \\
\hline
\end{tabular}

There were 170 kebeles in south Gondar. The sampling technique applied was multistage sampling [5 woredas (Ebnat, Farta, Fogera, Tach-gaynt \& Hamusit ), 12 kebeles and 528 households]. By simple random sampling (lottery method), 5 woredas and 12 kebeles were selected within the selected woredas considering the feasibility of this study. Proportional to size allocation of samples for each kebeles was conducted after the number of reproductive age women's were taken from family folder of respective health extension workers at kebele. Then, to access each women in each kebeles, systematic sampling technique, by the use of household numbers, was applied. Finally, reproductive age women in the selected households were interviewed. When there were more than one woman in a household, one of them the woman was selected by lottery method for interview. If sampled women were not found or if their home were closed, then data collectors were returned again in another day and interviewed.

\subsection{Variables of the study}

Unmet need for family planning was the dependent Variable; and the independent Variables were: Socio demographic variables like age, Residence, religion, educational background, education of husband, occupation of husband; reproductive factors: perceived risk of pregnancy, parity, number of children, desire number of children, menstrual status, unintended pregnancy and induced abortion; family planning factors: awareness on FP, place to access FP methods, side effect of FP methods, shortage of FP methods, and fear of infertility; health facility and Health provider's related factors: distance of health facility, waiting time, information given, appointment, free choice of FP methods; religious, cultural and traditional related factors: roles of religious leaders, religious desire to space, cultural factors, traditional factors, opposition from community leaders and fear of infidelity.

\subsection{Operational definition}

Unmet need for FP: women who are not pregnant and not in postpartum amenorrhea and are considered fecund and want to postpone their next birth for 2 or more years or stop childbearing altogether but are not using a contraceptive method or have a mistimed or unwanted current pregnancy, or are postpartum amenorrhea and their last birth in the last 2 years was mistimed or unwanted. So, unmet need of FP is who do not want any more children but not using any FP method (3). The dependent variable was unmet 
need for family planning and was dichotomized as having unmet need ( $1=$ yes) and absence of unmet need $(0=$ no).

\subsection{Data collection tools, procedures and Data Quality Control}

Data collection tools were adopted from roughly reviewing literatures. A pretested structured interviewer administered questioner were used and face to face interview were conducted to collect data. Data were collected by three BSc nurses after training for one day was given. In addition to the principal investigators, one experienced BSc nurse supervisor was assigned to lead the data collection, check for completeness and consistency of questioners, and to assist data collectors. If respondents did not exist, data collectors returned in next day and interviewed them again.

Pre-test was done on 26 (5\%) respondents in Makisegnit district, north Gondar before actual data collection. Supervision and on spot checking of the data collection procedures were made by assigned supervisor and principal investigator. Every day, at the end of the data collection process, discussion was conducted with the supervisor and data collectors, and problems encountered were identified and timely addressed. The completeness of the questionnaire was checked before data entry.

\subsection{Data processing and analysis}

After the data collection, it was checked for completeness and entered into Epi-info Version 7 and exported to SPSS Version 20 statistical software for statistical analysis. Descriptive analysis like frequency distribution, mean and standard deviation were computed to summarize data. In order to assess the association between unmet need of family planning and independent variables, bivariable analysis was performed. Then, variables with $\mathrm{p}$-value less than 0.25 were fitted into multivariable logistic regression model to identify statistically significantly associated variables with unmet needs of modern FP using p-value $\leq 0.05$ and adjusted odds ratio (AOR) at $95 \% \mathrm{Cl}$ were used to determine predictors of unmet need of family planning.

\subsection{Ethical consideration}

Ethical approval and clearance was taken from ethical review board of University of Gondar, College of Medicine and Health Sciences. Letter of permission to conduct the study was obtained from administrative office of South Gondar zone. Written informed consent was obtained from participants before data collection. They were informed that participating in the study was voluntarily. The right to withdraw from the study at any moment during the interview was assured. Teenagers (age 15, 16 and 17) were interviewed with their families to support the interview process. Confidentially of information was secured to keep their privacy.

\section{Result}


A total of 483 married women were participated in the study with the response rate of $91.4 \%$. Two hundred fifteen (44.5\%) of married reproductive age group women were aged 25-34 years with the mean age of 32 (SD \pm 7.916 ). The smallest age was 15 years and the highest age was 49 years. From 483 respondents, $112(23.2 \%)$ were living in urban area (Table 2$)$.

Table 2

Socio-demographic characteristics of married reproductive age women in South Gondar, Ethiopia, $2017(\mathrm{n}=483)$

\begin{tabular}{|c|c|c|c|}
\hline Variablescategory & & Frequency & Percent \\
\hline \multirow[t]{3}{*}{ Age } & $15-24$ & 113 & 23.4 \\
\hline & $25-34$ & 215 & 44.5 \\
\hline & $>=35$ & 155 & 32.1 \\
\hline \multirow[t]{2}{*}{ Residence } & Urban & 112 & 23.2 \\
\hline & Rural & 371 & 76.8 \\
\hline \multirow[t]{3}{*}{ Religion } & Muslim & 297 & 61.5 \\
\hline & Orthodox & 174 & 36.0 \\
\hline & Others* & 12 & 2.5 \\
\hline \multirow[t]{3}{*}{ Educational status of respondents } & no formal education & 162 & 33.5 \\
\hline & Primary & 265 & 54.9 \\
\hline & secondary and above & 56 & 11.6 \\
\hline - Others-protestant and catholic & & & \\
\hline
\end{tabular}

Most of the women 464 (96\%) were heard about modern FP from different sources. Moreover 374 (77\%) of respondents were current FP users. One hundred nine (23\%) of women were not using modern FP due to different reasons (Table 3 ). 
Table 3

Family planning related factors in South Gondar, Ethiopia, $2017(n=483)$.

\begin{tabular}{|c|c|c|c|}
\hline Variables & category & Frequency & $\begin{array}{l}\text { per } \\
\text { cent }\end{array}$ \\
\hline \multirow[t]{2}{*}{ Have you heard about modern FP } & Yes & 464 & 96.1 \\
\hline & No & 19 & 3.9 \\
\hline \multirow{6}{*}{$\begin{array}{l}\text { If yes where do you get the } \\
\text { information }\end{array}$} & Relatives and friends & 204 & 44.0 \\
\hline & Health professions & 154 & 33.2 \\
\hline & $\begin{array}{l}\text { Health professions, relatives and } \\
\text { friends }\end{array}$ & 47 & 10.1 \\
\hline & Husband & 28 & 6.0 \\
\hline & Media & 17 & 3.7 \\
\hline & Local news and magazines & 14 & 3.0 \\
\hline \multirow[t]{2}{*}{ Are you currently using modern FP? } & Yes & 374 & 77.4 \\
\hline & No & 109 & 22 \\
\hline \multirow[t]{5}{*}{ If yes from where? } & Health centre & 209 & 55.9 \\
\hline & Health post & 89 & 23.8 \\
\hline & Private clinic & 37 & 9.9 \\
\hline & Hospital & 26 & 7 \\
\hline & Drug store & 13 & 3.5 \\
\hline \multirow[t]{7}{*}{ If no reason } & No awareness & 30 & 27.5 \\
\hline & Pregnant & 26 & 23.9 \\
\hline & Husband influence & 19 & 17.4 \\
\hline & FP side effect & 17 & 15.6 \\
\hline & Fear of infertility & 9 & 8.3 \\
\hline & Use of traditional methods & 4 & 3.7 \\
\hline & Religion & 4 & 3.7 \\
\hline
\end{tabular}

\subsection{Health facility and health workers related factors}

From all respondents, $320(66 \%)$ were visited by health providers. The time taken for round trip to visit health institution were $<60$ minutes long for $329(68 \%)$ respondents. In addition, $110(23 \%)$ of the recnnndentc were enent their time in health inctitution for 30 minutes. Out of all 357 (74\%) of the Loading [MathJax]/jax/output/CommonHTML/fonts/TeX/fontdata.js 
respondents were told about FP options. An appointment had given for $332(88 \%)$ of the FP users (Table 4).

Table 4

Health facility and health workers related factors for unmet needs of modern family planning methods in South Gondar, Ethiopia, $2017(\mathrm{n}=483)$

\begin{tabular}{|llll|}
\hline Variables & Category & Frequency & Percent \\
\hline Have you visited by FP provider in last12 months? & Yes & 320 & 66.3 \\
\cline { 2 - 4 } & No & 163 & 33.7 \\
\hline Time taken for round trip & $0-60$ minutes & 329 & 68.1 \\
\hline Time taken in health facility & $>60$ minutes & 154 & 31.9 \\
\hline Have you told about FP options? & $0-30$ minutes & 110 & 22.8 \\
\hline If yes, do you get the method you want? & $>30$ minutes & 372 & 77.2 \\
\hline Do you get an appointment? & Yes & 357 & 74 \\
\hline & No & 126 & 26 \\
\hline Yes & No & 92 & 74.2 \\
\hline Res & Yes & 332 & 87.8 \\
\cline { 2 - 4 } & No & 46 & 12.2 \\
\hline
\end{tabular}

\subsection{Religious, cultural and traditional related factors}

Most of the respondents 432 (89\%) of married reproductive age women accept modern FP. Seventy six $(16 \%)$ of the respondents get opposition from religious leaders for FP utilization. One hundred seventy five $(36 \%)$ of respondents reported that there were traditional views in their community of these views 49 (28\%) said modern FP reduces body weight, $47(27 \%)$ reported that it results in difficulty to work with hand, $43(24.6 \%)$ of them said it causes menses to retain in the uterus and $36(20.6 \%)$ reported as it causes infertility (Table 5). 
Table 5

Religious, cultural and traditional related factors in South Gondar, Ethiopia, 2017 ( $n=483)$

\begin{tabular}{|c|c|c|c|}
\hline Variables & & Frequency & Per cent \\
\hline \multirow[t]{2}{*}{ Is modern FP accepted in your religion? } & Yes & 432 & 89.4 \\
\hline & No & 51 & 10.6 \\
\hline \multirow[t]{2}{*}{ Opposition from religious leaders } & Yes & 76 & 15.7 \\
\hline & No & 407 & 84.3 \\
\hline \multirow[t]{2}{*}{ Opposition from community leaders } & Yes & 42 & 8.7 \\
\hline & No & 441 & 91.3 \\
\hline \multirow[t]{2}{*}{ Are there traditional views on modern FP? } & Yes & 175 & 36.2 \\
\hline & No & 308 & 63.8 \\
\hline \multirow[t]{4}{*}{ If yes, what are they? } & losses body weight & 49 & 28.0 \\
\hline & difficult to work with hand & 47 & 26.9 \\
\hline & menses retain in the uterus & 43 & 24.6 \\
\hline & causes infertility & 36 & 20.6 \\
\hline
\end{tabular}

\subsection{Reproductive related factors characteristics}

Four hundred forty seven (92.5\%) of respondents were currently menstruating. Out of all 449 (93\%) of respondents had ever been pregnant. Four hundred thirty five (90\%) of the respondents were gave birth. Two hundred ninety four $(61 \%)$ of women desired to have $<5$ children. Eighty five $(17.6 \%)$ of respondents had history of unwanted pregnancy due to $56(65.9 \%)$ of them did not use modern FP methods. Only 34 $(7 \%)$ of the respondents had history of induced abortion due to $17(89.5 \%)$ of them did not use modern FP methods (Table 6). 
Table 6

Reproductive related factors characteristics of married reproductive age group women in South Gondar, Ethiopia, $2017(\mathrm{n}=483)$.

\begin{tabular}{|c|c|c|c|}
\hline Variables & Category & Frequency & percent \\
\hline \multirow[t]{2}{*}{ Are you currently menstruating } & Yes & 429 & 89.5 \\
\hline & No & 54 & 10.5 \\
\hline \multirow[t]{2}{*}{ Have you ever been pregnant } & No & 34 & 7.0 \\
\hline & Yes & 449 & 93.0 \\
\hline \multirow[t]{2}{*}{ give birth } & No & 48 & 9.9 \\
\hline & Yes & 435 & 90.1 \\
\hline \multirow[t]{2}{*}{ desire number of children } & $0-5$ & 294 & 60.9 \\
\hline & $>5$ & 189 & 39.1 \\
\hline \multirow[t]{2}{*}{ total alive children } & $0-5$ & 452 & 93.6 \\
\hline & $>5$ & 31 & 6.4 \\
\hline \multirow[t]{2}{*}{ History of unintended pregnancy } & No & 398 & 82.4 \\
\hline & Yes & 85 & 17.6 \\
\hline \multirow[t]{3}{*}{ if yes reason } & do not use modern FP & 56 & 65.9 \\
\hline & mistimed use of modern FP & 26 & 30.6 \\
\hline & failure of modern FP & 3 & 3.5 \\
\hline \multirow[t]{2}{*}{ Have you history of induced abortion } & No & 449 & 93.0 \\
\hline & Yes & 34 & 7.0 \\
\hline \multirow[t]{2}{*}{ if yes reason } & do not use modern FP & 17 & 89.5 \\
\hline & failure of modern FP & 2 & 10.5 \\
\hline
\end{tabular}

\subsection{Unmet need of modern family planning}

The overall unmet need of modern family planning in the study area was $22.6 \%$ at $95 \% \mathrm{Cl}$ : $(18.8 \%-$ 26.5\%).

\subsection{Factors associated to unmet need of modern FP}

The results of bivariable and multivariable logistic regression model showed that reproductive aged women visited by health care providers, currently menstruating, having desired number of children and induced abortion were found statistically significantly associated with unmet needs of modern FP. 
Women who had not been visited by health care providers within 12 months prior to the study period were 0.34 times less likely to have unmet need of modern FP compared to women who had been visited (AOR $=0.34,95 \% \mathrm{Cl}:(0.21-0.54))$. Women who do not currently menstruating were 3.75 times more likely to have unmet need for FP (AOR $=3.75,95 \% \mathrm{Cl}$ : (1.48-13.0)) and those women who had desired to have $>5$ children were 0.47 times less likely to have unmet need for FP (AOR $=0.47,95 \% \mathrm{Cl}$ : $(0.38-0.74))$. Finally, women who had no induced abortion history were 1.3 times more likely to have unmet need of modern family planning methods (AOR 1.30 95\% Cl: (1.01-7.91)) (Table 7).

Table 7

Factors associated with unmet need of modern family planning among married reproductive aged women in South Gondar, Ethiopia, $2017(n=483)$

\begin{tabular}{|c|c|c|c|c|}
\hline \multirow[t]{2}{*}{ Explanatory variables } & \multicolumn{2}{|c|}{ Unmet need } & \multirow[t]{2}{*}{$\operatorname{COR}(95 \% \mathrm{Cl})$} & \multirow[t]{2}{*}{$\operatorname{AOR}(95 \% \mathrm{Cl})$} \\
\hline & Yes & No & & \\
\hline \multicolumn{5}{|l|}{ Residence } \\
\hline Urban & 32 & 80 & 1 & 1 \\
\hline Rural & 77 & 294 & $0.65(0.36-0.94)$ & $0.43(0.29-0.61)$ \\
\hline \multicolumn{5}{|l|}{ Visited by providers } \\
\hline Yes & 54 & 266 & $0.39(0.26-0.62)$ & $0.34(0.21-0.54)$ * \\
\hline No & 55 & 108 & 1 & 1 \\
\hline \multicolumn{5}{|l|}{ Currently Menstruating } \\
\hline Yes & 90 & 339 & 1 & 1 \\
\hline No & 19 & 35 & $2.04(1.51-10.35)$ & $3.75(1.48-13)$ * \\
\hline \multicolumn{5}{|l|}{ Desire no children } \\
\hline $0-5$ & 82 & 212 & 1 & 1 \\
\hline$>5$ & 27 & 162 & $0.43(0.27-0.70)$ & $0.47(0.38-0.74)$ * \\
\hline \multicolumn{5}{|c|}{ History of Induced abortion } \\
\hline Yes & 14 & 20 & 1 & 1 \\
\hline No & 105 & 344 & $2.29(1.79-6.65)$ & $1.30(1.91-7.91)$ * \\
\hline \multicolumn{5}{|l|}{ Give birth } \\
\hline Yes & 103 & 332 & $2.17(1.90-5.25)$ & $3.23(2.1-5.7)$ \\
\hline No & 12 & 36 & 1 & 1 \\
\hline
\end{tabular}




\section{Discussion}

This study tried to assess the prevalence of unmet need of modern family planning among married reproductive aged women in South Gondar, Ethiopia. The proportion of unmet need was found to be $22.6 \%$ at $95 \% \mathrm{Cl}$ : (18.8-26.5). Of this, $15.1 \%$ of total unmet need was unmet need for spacing and $7.5 \%$ of total unmet need was unmet need for limiting. This finding was in line with the prevalence of unmet need in Africa (22\%), Ethiopian national prevalence of unmet need $(22 \%)(13 \%$ for spacing and $9 \%$ for limiting) and a study conducted in Tigray region, Ethiopia $21.4 \%$ (14.5\% for spacing and $6.9 \%$ for limiting) $(3,9,30)$ respectively.

On the other side, this finding was higher than world unmet need of family planning in 2017 (12\%), unmet need in Oceania (15\%), North America (10\%), Latin America (10\%), Asia (10\%), and Caribbean (9\%) (2).These variations may be due to difference in the level of awareness of study participants. Other possible explanations for the observed variations could be research design, culture and population differences.

The result of this study revealed that significant association between women not visited by health providers towards unmet need of modern FP. The odds of unmet need of modern FP among married reproductive age group women who did not visited by health care providers were 0.34 times lower than women who were visited by health providers within the last 12 months before this study period. This finding was different in direction with the previous study done in Enemay woreda, North West Ethiopia (15). Those who had not visited were more likely to have unmet need than visited. This variation may be due to research design.

The result also showed that the presence of significant association between desire number of children and unmet need of modern family planning. The probabilities of women who had desire of $>5$ children were 0.47 times lower than women who had desired $0-5$ children. Even if people need different family size, as number of children increase, the probability of using modern family planning will also increases. This study is in contrast with study done in Tigray (9). This difference may be due to difference of awareness levels on importance of planning family size.

Women who did not menstruating had 3.75 times more likely to have unmet need than women who were menstruating. This study is in line with study done in Enemay woreda (15). This may be due to similarity in study design.

Married women who had no history of induced abortion had 1.3 times higher unmet need of modern family planning than who had induced abortion history. Because women with history of induced abortion have more awareness in reducing unmet need than others. This study is in congruent with the study done by Kelemu Chafo and Feleke Doyore (27). This similarity would be due to study design and sampling procedure. 
Limitations of the study given the great role men play in decision making concerning unmet need, this research has a weakness that it did not evaluate unmet need among men. In addition our definition for unmet need was not directly applicable to sexually active women out of union given that other parameters are to be taken into consideration. Our study did not evaluate the supply and delivery of the family planning services which could be possible factors influencing unmet need.

\section{Conclusions}

Unmet need for FP was found to be high in the study area as compared to world and national prevalence. Women visited by health care providers, currently menstruating, desire number of children and history of induced abortion were significantly associated with unmet need of modern FP. Health care providers and health extension workers need to visit regularly and promote appropriate and active IEC programs that address provision of accurate information about availability of the services and various contraceptive options including techniques to reduce and change perceived barriers to service utilization (such as rumors and misconceptions of FP).

\section{Abbreviations/acronyms}

AOR: Adjusted Odds Ratio CMW: Currently Married Women CPR: Contraceptive Prevalence Rate; DC: Data Collector; DHS: Demographic and Health Survey, EDHS: Ethiopian Demographic and Health Survey FP:

Family Planning, GC: Gregorian calendar; HEWs: Health Extension Workers; PI: Principal Investigator; TFR: Total Fertility Rate; WU: Wollo University

\section{Declarations}

\section{Ethics approval and consent to participate}

Ethical clearance and approval letter was obtained from the University Gondar Ethical Review board. Written informed consent was provided to participants. Confidentiality of respondent's information was secured.

\section{Consent for publication}

Not applicable

\section{Availability of Data and materials}

All the data supporting the findings are within the manuscript. Additional detailed information and raw data are available from the corresponding author on reasonable request. 


\section{Competing Interests}

The authors have declared that no competing interests exist in the publication of this paper.

\section{Funding:}

University of Gondar

\section{Authors' contribution}

MG has been involved in the conception, design, analysis, interpretation, and report and manuscript writing. GE was also involved in the design, analysis, interpretation of the data, and manuscript writing. Both authors read and approved the final manuscript.

\section{Acknowledgments}

First we would like to thank all study participants for their cooperation in providing the necessary information. We would also thank data collectors and supervisors for the devotion and quality work during data collection.

\section{References}

1. Sedgh G. Unmet Need for Contraception in Developing Countries: Examining. Women's. Reasons for Not Using a Method. New York: Guttmacher Institute; 2016.

2. United Nations. Department of Economic and Social Affairs, Population Division. World Family Planning, 2017.

3. Central statistical agency. Ethiopian demographic and health survey. Addis Abeba, Ethiopian central statistical agency; 2016.

4. Wulifan JK, Brenner S, Jahn A, De Allegri M. A scoping review on determinants of unmet need for family planning among women of reproductive age in low and middle income countries.BMC women's health. 2015.

5. MacQuarrie KL. Unmet need for family planning among young women: levels and trends. USAID 2014.

6. Gebreselassie T, Govindasamy P. Levels and trends in unmet need for family planning among adolescents and young women in Ethiopia 2013.

7. Mota K, Reddy S, Getachew B. Unmet need of long-acting and permanent family planning methods among women in the reproductive age group in shashemene town, Oromia region, Ethiopia: a cross sectional studv RMC, women's health 2015 
8. Hailemariam A, Haddis F. Factor's affecting unmet need for family planning in southern nations. Ethiopia: nationalities and peoples region; 2011.

9. Gebre G, Birhan N, Gebreslasie K. Prevalence and factors associated with unmet need for family planning among the currently married reproductive age women in Shire-Enda-Slassie, Northern West of Tigray, Ethiopia 2015: a community based cross-sectional study. Pan African Medical Journal. 2016.

10. Motlaq ME, Eslami M, Yazdanpanah M, Nakhaee N. Contraceptive use and unmet need for family planning in Iran. International Journal of Gynecology \& Obstetrics. 2013.

11. Prusty RK. Use of contraceptives and unmet need for family planning among tribal women in India and selected hilly states.Journal of health, population, and nutrition. 2014.

12. Palamuleni 12AdebowaleSA. ME. Determinants of unmet need for modern contraception and reasons for non-use among married women in rural areas of Burkina Faso. African Population Studies. 2014.

13. Omwago MO, Khasakhala AA. Factors influencing couples' unmet need for contraception in Kenya.African population studies. 2013.

14. Mekonnen W, Worku A. Determinants of low family planning use and high unmet need in Butajira District, South Central Ethiopia. Reproductive Health. 2011.

15. Dejenu G, Ayichiluhm M, Abajobir AA. Prevalence and Associated Factors of Unmet need for Family Planning among Married Women in Enemay District, Northwest Ethiopia: A Comparative CrossSectional Study. Global Journal of Medical Research.2013.

16. Dejenu G, Ayichiluhm M, Abajobir AA. Prevalence and Associated Factors of Unmet need for Family Planning among Married Women in Enemay District, Northwest Ethiopia: A Comparative CrossSectional Study. Global Journal of Medical Research.2013.

17. Ajong AB, Njotang PN, Yakum MN, Essi MJ, Essiben F, Eko FE, Kenfack B, Mbu ER. Determinants of unmet need for family planning among women in Urban Cameroon: a cross sectional survey in the Biyem-Assi Health District, Yaoundé. BMC women's health. 2015.

18. Genet $\mathrm{E}$, Abeje G, Ejigu T. Determinants of unmet need for family planning among currently married women in Dangila town administration, Awi Zone, Amhara regional state; a cross sectional study. Reproductive health. 2015.

19. Yadav D, Dhillon P. Assessing the impact of family planning advice on unmet need and contraceptive use among currently married women in Uttar Pradesh, India. PloS one. 2015.

20. Nyauchi B, Omedi G. Determinants of unmet need for family planning among women in rural Kenya. African Population Studies. 2014.

21. Tegegn M, Arefaynie M, Tiruye TY. Unmet need for modern contraceptives and associated factors among women in the extended postpartum period in Dessie town, Ethiopia. Contraception and reproductive medicine. 2017.

22. Alemayehu M, Lemma H, Abrha K, Adama Y, Fisseha G, Yebyo H, Gebeye E, Negash K, Yousuf J, Loading [MathJax]/jax/output/CommonHTML/fonts/TeX/fontdata.js :sociated factors among pastoralist community 
of afar region, eastern Ethiopia. BMC women's health. 2016.

23. Magure TM, Manene T, Munjanja SP, Bradley SE, Mishra V. Trends in unmet need and the demand for family planning in Zimbabwe 2014.

24. New JR, Cahill N, Stover J, Gupta YP, Alkema L. Levels and trends in contraceptive prevalence, unmet need, and demand for family planning for 29 states and union territories in India: a modelling study using the Family Planning Estimation Tool. The Lancet Global Health. 2017.

25. Pasha O, Goudar SS, Patel A, Garces A, Esamai F, Chomba E, Moore JL, Kodkany BS, Saleem S, Derman RJ, Liechty EA. Postpartum contraceptive use and unmet need for family planning in five low-income countries. Reproductive health. 2015.

26. Quality of Family Planning Service in the Health Facilities of East Shoa Zone, Oromia Regional State, Ethiopia27. Asnake M, Henry EG, Tilahun Y, Oliveras E. Addressing unmet need for long-acting family planning in Ethiopia: Uptake of single-rod progestogen contraceptive implants (Implanon) and characteristics of users. International Journal of Gynecology \& Obstetrics 2013.

27. Chafo KD, Doyore F. Unmet need for family planning and associated factors among currently married women in Misha District, Southern Ethiopia: A cross sectional study. J Women'sHealthCare.2014;3(165):2167 - 0420. 29.. Ali Okud AA. A. Factors affecting unmet need for family planning in Eastern Sudan. BMCPublicHealth2013.

28. Ministry of health. Ethiopian health sector transformation plan. Addis Ababa, the Federal Democratic Republic of Ethiopia Ministry of Health, 2015.

29. Clelajnd JCAA, Peterson H, Ross J, Tsui A. Contraception and health. Lancet. 2012. 